\title{
Sobre la complejidad y dificultad de las lenguas. El caso del euskera*
}

\author{
Juan CARlos Moreno CABrera
}

(UAM)

\section{INTRODUCCIÓN}

Es muy frecuente oír que tal o cual lengua, al tener una estructura gramatical o fónica muy compleja, es difícil de aprender como lengua segunda. Esto se suele aplicar con llamativa frecuencia, dentro de nuestros ámbitos, a las lenguas no indoeuropeas, es decir, a aquellas lenguas que no pertenecen a la gran familia de lenguas europeas entre las que están las más conocidas y extendidas, tales como el francés, el inglés o el español.

Esta característica de esas lenguas europeas no indoeuropeas (finés, húngaro, euskera) se suele atribuir de forma claramente errónea a algunas propiedades intrínsecas de esas lenguas, que las hacen especialmente difíciles. De esta forma, se pasa de la idea de que el húngaro, finés o euskera son lenguas difíciles de aprender como lengua segunda para hablantes de lengua primera indoeuropea, a la idea de que estas lenguas son intrínsecamente difíciles por sus características lingüísticas internas (normalmente léxicas y/o sintácticas); es decir, por tener una estructura gramatical muy compleja. He aquí un párrafo extraído de una página web.

Varios lingüistas dicen que el húngaro es la lengua más difícil de toda Europa y una de las más complicadas del mundo. El estonio, el euskera, el saami, el maltés, el finés y el húngaro no son de origen indoeuropeo como el castellano, francés o italiano. En la actualidad una lengua que no es de origen indoeuropeo sin duda corre riesgo de ser considerada difícil. Esto si se relaciona con la acción intelectual de aprenderla y hablarla.

(http://quincenal.uw.hu/2006_09_05/articulos/hungaro.htm)

Esta idea de la mayor complejidad y dificultad está claramente injustificada: el húngaro, finés y euskera les resultan más difíciles de aprender a los hablantes

* Este trabajo ha sido financiado por el Ministerio de Educación y Ciencia y los fondos FEDER mediante el proyecto de investigación Aspectos Evolutivos y Tipológicos de la Complejidad Lingüística (HUM2006-05118) 
de lenguas indoeuropeas no porque sean lenguas intrínsecamente difíciles, sino porque no son lenguas indoeuropeas. Por tanto, la dificultad o facilidad de las lenguas no es un rasgo de esas lenguas en sí sino de la relación de unas lenguas con otras (a través de sus hablantes). Ciertamente, para un hispanohablante el euskera es más difícil de aprender que el catalán; pero ello no se debe a que el euskera tenga una estructura gramatical más complicada que el catalán. La prueba irrefutable de ello es que para un euskaldún monolingüe guipuzcoano es mucho más fácil aprender vizcaíno o suletino que aprender catalán o castellano. Ello se debe a que el guipuzcoano, el vizcaíno y el suletino son dialectos euskéricos.

Como dice el lingüista neerlandés W. Kusters después de haber analizado los conceptos de simplicidad y complejidad de las lenguas:

La moraleja de esta historia es que no hay manera de definir la complejidad sin hacer referencia a para quién es o no compleja una lengua. En otras palabras, la complejidad no es predicado simple atribuible a la lengua, sino una relación entre dos entidades: una lengua y alguien que evalúa la lengua.»

(Kusters 2003: 6, negrita del autor)

Antes de seguir adelante, es necesario justificar la idea de que, de forma intrínseca, ni el húngaro, ni el finés, ni el euskera son lenguas más complejas y difíciles que las restantes lenguas indoeuropeas de Europa. Esto se puede comprobar fácilmente cuando estas lenguas se aprenden y usan como lenguas primeras. Los niños húngaros, fineses y euskaldunes adquieren estas lenguas de forma totalmente análoga a como se aprenden en la infancia el francés, inglés o castellano: ni tardan más en adquirirlo, ni tienen más dificultades para ello que para adquirir las lenguas indoeuropeas. Una vez adquiridas de niño estas lenguas, los hablantes adultos fineses, húngaros y euskaldunes usan sus lenguas con evidente facilidad, fluidez y naturalidad. Podemos constatar empíricamente que los hablantes de húngaro no tardan más en decir las cosas que desean decir que los hablantes de francés: ambos hablan de forma natural con rapidez, fluidez y facilidad. Por consiguiente, no existen lenguas que sean tan difíciles que sus hablantes tarden muchos años en adquirirlas y tengan que hablarlas de adultos con lentitud y mucha atención para no equivocarse. El euskaldún, el finés y el húngaro se expresan en sus lenguas con la misma facilidad, rapidez y eficacia con la que lo hacen los hablantes de francés, inglés o castellano. Este es un hecho objetivo que es muy difícil rebatir y que pone de manifiesto que no hay lenguas simples y complejas, fáciles y lenguas difíciles.

Hasta aquí me he referido a las lenguas orales coloquiales, que son lenguas naturales adquiridas en la infancia de modo espontáneo y usadas en la edad adulta sin hacer ningún esfuerzo ni reflexión, ni ejercer ningún control consciente. Se trata del habla oral informal.

Sin embargo, existe otra realidad, que es la lengua estándar escrita. Esta lengua estándar escrita o literaria es una elaboración artificial de una o varias de las variedades orales espontáneas y, por ello, deja de ser una lengua natural como la caracterizada en los párrafos anteriores. Esta lengua estándar no se aprende es- 
pontáneamente, sino que se enseña en la escuela y, normalmente, es difícil de adquirir y manejar. Cuanto más se aleje la lengua estándar de la variedad lingüística de quien la aprende, más difícil le parecerá. Por ejemplo, a un niño hablante del dialecto castellano la lengua estándar española le parecerá más fácil que a un niño hablante de un dialecto andaluz; de modo similar, a un niño hablante de dialecto guipuzcoano, el euskera batua le parecerá más fácil que a un niño hablante de dialecto vizcaíno. Ello se debe a que el español estándar es muy próximo, si no idéntico, al dialecto castellano moderno y el euskera batua está en algunos aspectos, más próximo al guipuzcoano que al vizcaíno.

Pero hay otro factor de las lenguas estándares, literarias o religiosas que las hacen mucho más artificiales que las lenguas orales espontáneas. Normalmente, esas lenguas estándares surgen de una serie de procesos de elaboración léxica, morfológica y sintáctica de alguna variedad o lengua oral espontánea que las convierten en lenguas artificiosas, no naturales. Este carácter artificioso despoja las lenguas orales de las propiedades naturales que las hacen adquiribles y utilizables de forma espontánea, de manera que se hacen difíciles de adquirir y de usar (puesto que han sido desnaturalizadas). Un ejemplo palmario de esto son las lenguas clásicas como el latín clásico, el árabe clásico o el sánscrito. He aquí un pasaje de un método moderno de lengua sánscrita:

Las lenguas vivas, naturales o aprendidas, cambian y se desarrollan. Pero cuando una lengua aprendida tal como el inglés literario está fuertemente ligada a y continuamente revitalizada por un idioma natural, sus oportunidades para una crecimiento independiente están limitadas. El sánscrito nos proporciona un ejemplo fascinante de una lengua que se desarrolla de modo totalmente independiente de esos condicionantes como un instrumento de expresión intelectual y artística.

(Coulson 1976: xxii)

Se trata de lenguas basadas en elaboraciones profundas de unas determinadas lenguas orales espontáneas, que las hacen artificiosas, y difíciles de adquirir y de usar. Ello es así porque no son lenguas naturales, sino artificiales y no se transmiten naturalmente de generación en generación, sino solo a través del estudio, por lo que solamente una proporción pequeña de la población es capaz de usarlas por escrito y oralmente de forma más o menos automática.

Por tanto, hay que distinguir entre las lenguas naturales y las lenguas cultivadas que se elaboran a partir de ellas (Moreno Cabrera 2006: 20-26). Todas las lenguas naturales, las lenguas orales espontáneas incluidas, por supuesto, el finés, el húngaro o el euskera, tienen un grado de facilidad o dificultad similar, dado que son adquiridas por los niños de forma espontánea y son usadas por los adultos de forma automática e irreflexiva, sin tener que hacer ningún esfuerzo consciente. En cuanto a las lenguas cultivadas, los idiomas que se elaboran y se modifican de forma consciente y deliberada de acuerdo con una serie de criterios religiosos, culturales, sociales o políticos, pueden tener diversos grados de dificultad según se aproximen más o menos a una variedad natural concreta o según hayan sufrido reelaboraciones lingüísticas más o menos radicales. Las lenguas 
estándar son lenguas cultivadas, no naturales y, por tanto, no tienen las características señaladas de las lenguas naturales.

En este sentido, es muy importante analizar, como haré en este trabajo, la imagen que se nos da de una lengua a través de la escritura, que es un medio artificial, no natural, de funcionamiento lingüístico. Como vamos a ver, nuestros juicios sobre la complejidad, facilidad y dificultad de las lenguas se basan primordialmente en la escritura y, por tanto, no son indicativos de esas propiedades, dado que la escritura supone una deformación importante de muchos aspectos de las lenguas naturales, que puede llevarnos a hacer juicios engañosos sobre la supuesta complejidad, dificultad o facilidad de las lenguas, tal como vamos a comprobar en el caso de la comparación entre el euskera y el castellano.

\section{LA SUPUESTA COMPLEJIDAD Y DIFICULTAD DEL EUSKERA}

Muchas veces, las impresiones de complejidad y dificultad que induce el aprendizaje de una lengua no-indoeuropea sobre los hablantes de lenguas indoeuropeas, se intentan justificar buscando determinadas propiedades lingüísticas de ellas para convertir en propiedades absolutas de carácter lingüístico, lo que no es más que una impresión superficial de carácter relacional o subjetivo. El caso del euskera es paradigmático en este sentido. El euskera, como lengua no indoeuropea y, por tanto, no romance, es muy diferente en muchos aspectos gramaticales del castellano, catalán, gallego o francés; esto hace que no sea fácil de adquirir como lengua segunda por hablantes de estos idiomas. Pero de ahí no puede deducirse que el euskera sea una lengua más compleja que las lenguas mencionadas y por tanto, más difícil que ellas. A pesar de ello, cuando se contrastan lingüísticamente, por ejemplo, el castellano y el euskera se suelen enfocar los aspectos más sencillos o simples de la primera lengua y los más complejos de la segunda para dar credibilidad objetiva a esa presunción de complejidad y dificultad que se le asigna al euskera. Para ilustrar este punto vamos a comparar la caracterización gramatical del castellano y del euskera que se hace en un libro de información general sobre las lenguas del mundo (del Moral 2002: 184-185, para el castellano y 192-193 para el euskera).

Entre los rasgos lingüísticos del castellano incluidos en el libro citado tenemos los siguientes:

\section{Características lingüísticas del castellano}

- «En cuanto a las vocales se distingue entre las lenguas latinas por la simpleza y claridad de su sistema.» (Del Moral 2002: 184)

- «El verbo distingue tres modos (...) y una numerosa variedad de tiempos para señalar el pasado. El futuro de indicativo tiende a expresarse cada vez más con el presente (...) El futuro de subjuntivo ha desaparecido...» (Del Moral 2002: 185) 
- «El español del norte [...] sigue ocupando un lugar preferente que garantiza, por su homogeneidad, la cohesión lingüística.» (Del Moral 2002: 185)

- «La extensión de la lengua por territorios tan alejados entre sí no pone en peligro la fragmentación. La unidad persiste en el sistema vocálico y consonántico, en el funcionamiento del género y del número, en las desinencias personales, temporales y modales del verbo....» (Del Moral 2002: 185)

La visión que se nos da en estas líneas que caracterizan el castellano (y en las demás de la obra citada que no reproduzco aquí para no alargar la cita excesivamente) es la de homogeneidad, estabilidad, simplicidad, consistencia, coherencia y facilidad. Se señala la pureza del sistema de las cinco vocales, que es un tópico de la ideología nacionalista española que se remonta a Menéndez Pidal (Moreno Cabrera 2008: 78-79). Cuando se habla del verbo en seguida se mencionan dos aspectos simplificadores: la sustitución del futuro por el presente y la pérdida del futuro de subjuntivo. Luego se recurre a la idea de que el modelo castellano, «el español del norte», presenta la mayor homogeneidad y de que, a pesar de su extensión inmensa, no hay una fragmentación importante apreciable.

Vemos en este pasaje cómo los aspectos intrínsecamente lingüísticos (vocales, tiempos verbales) se conjugan con los sociolingüísticos (modelos de lengua, extensión geográfica) para ofrecernos un panorama de una lengua cohesionada, homogénea y desprovista de complejidades. kera:

Pasemos ahora a la caracterización que en esa misma obra se nos da del eus-

\section{Características lingüísticas del euskera}

- «Tiene el vasco cinco vocales.» (Del Moral 2002: 192)

- «Los nombres no distinguen género. Se declinan en once casos.» (Del Moral 2002: 192)

- «Dispone de un centenar de sufijos para formar derivados de todo tipo.» (Del Moral 2002: 193)

- «El verbo es de una enorme complejidad frente al relativamente simple sistema nominal. Tiene formas personales e impersonales, simples y compuestas con varios verbos auxiliares ricos en formas que presentan un gran número de irregularidades.» (Del Moral 2002: 193)

- «Las diferencias entre los grupos de dialectos, aunque no están tan acentuadas como para impedir la comunicación, sí la dificultan.» (Del Moral 2002: 193)

Es muy curioso que el rasgo de las cinco vocales que se considera tan importante para definir la accesibilidad del español, su cohesión y su facilidad de 
extensión, no se utilice aquí con los mismos fines. En la caracterización anterior del castellano, coincidente con el correspondiente tópico del nacionalismo lingüístico español, se utiliza precisamente para explicar la supuesta cohesión de esta lengua. Pero en el caso del vasco este rasgo, que se considera tan importante en el caso del castellano, no parece que pueda impedir las dificultades de comunicación entre dialectos que se señalan al final. Por otro lado, se utilizan caracterizaciones imprecisas como la del «centenar de sufijos de para formar derivados de todo tipo» que contribuyen también a dar una imagen de anarquía, irregularidad y dispersión respecto del euskera, que se contrapone a la regularidad, cohesión y consistencia del castellano. No se dice que las diferencias dialectales del castellano dificulten la comunicación, esto queda sólo para las diferencias dialectales euskéricas.

Pero donde se nota de forma más patente la manipulación ideológica consistente en adscribir a la estructura lingüística una serie de propiedades políticamente asignadas a una lengua, es en la caracterización del verbo. El verbo es, según la caracterización que examinamos de «enorme complejidad»y, además, presenta un gran número de irregularidades. Ninguno de estos adjetivos y valoraciones se mencionan en el caso del verbo español. Sin embargo, es fácil argüir que esta caracterización es claramente falsa. No se puede mantener de ninguna manera que el verbo euskérico sea más complejo e irregular que el verbo castellano; al revés, parece haber más datos para pensar justamente lo contrario. El verbo castellano, como el de las demás lenguas romances hermanas, está plagado de irregularidades desconocidas en el verbo vasco.

Para darnos cuenta de esto, comparemos la flexión en presente de indicativo de dos verbos de la segunda conjugación: cocer y conocer. Ambos verbos son irregulares, pero, a pesar de su proximidad fonética y de ser de la misma conjugación no podemos basarnos en el primero para deducir la conjugación del segundo. En efecto de cuezo, cueces, cuece, cocemos o cueza no podemos deducir las formas correspondientes del verbo conocer, que habrían de ser, siguiendo, el modelo del verbo cocer: cuenozo (frente a conozco), cuenoces (frente a conoces), cuenoce (frente a conoce), conocemos (esta vez, es la forma correcta) y cuenoza ( frente a conozca). Por supuesto, tampoco podemos hacer lo contrario, es decir, deducir las formas conjugadas del verbo cocer a partir de las del verbo conocer. Lo cierto es que los paradigmas verbales del español y de las demás lenguas romances están llenos de este tipo de irregularidades. Esto ya fue observado por Larramendi, quien lo contrasta con la regularidad de la conjugación vasca:

En las conjugaciones tiene el vascuence la misma certidumbre de reglas (...) en todos tres del guipuzcoano, vizcaíno, labortano, las reglas son fijas, y que no admiten excepciones. Y, ¿qué hay en latín, romance, francés y otras lenguas?, ¿qué ha de haber?: confusión y nada más. Dice el romance: los verbos en ar se conjugan como amo, amas. Engáñanos, porque sonar se conjuga de otra manera: sueno, suenas, suena, y perdióse la $o$ del infinitivo: cóbrale al instante sonamos, sonáis, y vuelta otra vez a perderla suenan. Diráse por ventura, que la regla es fija para esas mudanzas, no en los acabados en ar, sí, en los acabados en onar, como sonar, sueno, suenas; tronar, trueno, truenas; soñar, sueño, sueñas. Pero también engaña; porque abandonar, entonar, donar, perdonar, con- 
donar, enconar, abonar, se acaban en onar, y no tienen tales anomalías, ni dice abandueno, abanduenas, etc.

(Larramendi 1728 (2000): 109-110)

¿Cuántos verbos irregulares hay en castellano? Si consultamos el Esbozo de la RAE (RAE 1973), encontramos enumerados, entre las páginas 313 y 328 de la sección dedicada a la conjugación irregular (\$2.12, 270-328), unos pocos más de 650 verbos. Sin embargo es posible encontrar listas más amplias. Por ejemplo, en el diccionario ruso-español de Nogueira y Turover (1992: 972-975) encontramos una lista de más de 900 verbos irregulares.

Frente a ello, el euskera presenta unos paradigmas verbales en los que la regularidad es claramente dominante.

En primer lugar, en el euskera actual solo se conjugan sintéticamente una docena de verbos, que de Rijk denomina strong verbs ('verbos fuertes'):

En el vasco hablado actualmente, hay solo dos docenas de verbos fuertes. Antes había más, pero incluso en el siglo XVI su número no superaba 50.

(De Rijk 2008: 116)

En la gramática de los Zubiri (2000: 463-482) aparece la conjugación sintéctica de 19 verbos. Solo uno de ellos presenta un irregularidad: el verbo *io 'decir', que tiene dos raíces. En la gramática de la Euskaltzaindia (1987: 221349) encontramos la conjugación sintética regular de hasta 24 verbos.

El resto de los verbos vascos, la inmensa mayoría, se conjugan mediante perífrasis con dos auxiliares izan ('ser') y *edun ('tener'), que es una raíz verbal reconstruida. Estos verbos, según los tiempos y los modos, toman diferentes raíces. Así, el primero izan, alterna con la raíz *edin y el segundo, *edun, alterna con la raíz *ezan (Euskaltzaindia 1987: 168-219). Esta es la única irregularidad sistemática del verbo euskérico, dado que las formas de las diferentes raíces son regulares.

Por tanto, podríamos decir perfectamente que, frente a los varios centenares de verbos irregulares del castellano, el euskera estándar presenta solo tres verbos irregulares (por su carácter polirrizo): *io 'decir', izan 'ser' y *edun 'tener'.

Desde el punto de vista de la estructura verbal morfológica no se puede mantener que el euskera sea más complejo que el castellano; en todo caso, cabría decir exactamente lo contrario.

A veces se dice que lo que da mayor dificultad al verbo vasco es la referencia en sus formas verbales tanto al sujeto, como al objeto directo y al objeto indirecto. Esta característica es señalada en el libro de R. del Moral a que he hecho referencia anteriormente:

El verbo vasco, en la frase, viene a ser un sumario de todos los nombres de la oración. Es decir, contiene en su propia forma una referencia al complemento directo y al indirecto. 
Veamos, para ilustrar este punto, algunas formas del verbo ekarri 'traer' en las que señalamos con letras más grandes las referencias a los participantes:

- DAKARZKIOT 'Se los traigo (a él)'

- DAKARZKIDaZU 'Me los trae (usted)'

- dakarZkiZUET 'Os los traigo'

- DAKARZKIEGU 'Se los traemos (a ellos)'

Tenemos aquí algunas de las formas pluripersonales de uno los pocos verbos euskéricos con conjugación sintética, sin auxiliar. En la primera forma observamos el morfema $z-$, que señala un paciente plural de tercera persona (el los de la traducción castellana), el morfema $o$-, que denota un destinatario de tercera persona de singular (el $s e$ de la traducción castellana) y el morfema final - $t$, que indica el agente de primera persona del singular). Las tres formas siguientes se analizan de modo análogo mutatis mutandis. De esta manera, el sufijo - gu (idéntico al pronombre $g u$ 'nosotros') de la cuarta forma denota el agente de primera persona del plural y el sufijo - $z u$ (idéntico al pronombre $z u$ 'usted') de la segunda denota el agente de segunda persona del singular en uso formal.

Esta incorporación de los participantes en el verbo se considera un rasgo del euskera que lo hace complejo y, por tanto, difícil. Pero es que, si lo observamos reflexivamente, podemos comprobar que el castellano también incorpora a las forma verbales una referencia pronominal a los participantes en el suceso descrito. A pesar de la escritura, una expresión como se los traigo es una unidad fónica y morfológica en la lengua hablada normal. Es decir, en realidad se los traigo no consta de tres unidades tal como nos sugiere la forma escrita, sino de una unidad integrada por el verbo más dos elementos proclíticos que conforman con él un elemento no descomponible. Como ocurre con la forma euskérica correspondiente, no podemos variar un ápice el orden de los elementos; es decir, no podemos tener cosas como *los se traigo, *se traigo los, *los traigo se, *traigo los se. Solo se da la posibilidad tráigoselos, desusada en el habla espontánea normal. Además, estos dos clíticos que se escriben por separado (se y los) no tienen autonomía sintáctica alguna; por ello, la siguiente oración no puede tener variantes como las que se enumeran a continuación:

- Los coches se los traigo yo a Pedro

- *Se los coches los traigo yo a Pedro

- *Los coches se traigo yo los a Pedro

- *Los los coches se traigo yo a Pedro

- *Los coches traigo yo a se los Pedro

- *Se los coches traigo yo a Pedro los

Baste esta casuística para poner de manifiesto que se los traigo funciona sintácticamente como una unidad indivisible que se manifiesta también en el hecho 
de que constituye también una palabra prosódica unitaria. Por consiguiente, no sería descabellado escribir esta expresión como selostraigo, de modo análogo a como se hace con las forma enclíticas correspondiente (tráelo, tráeselo, traédnoslo).

Esto significa, entonces, que el verbo castellano también es pluripersonal, como ocurre con el euskérico. Por supuesto, entre una forma como dakarzkiegu y se los traemos, aunque comparten como mínimo el ser una unidad sintáctica y prosódica, hay diferencias. En la forma euskérica lo que más se parece a los clíticos castellanos es la terminación - $g u$, que, como he observado ya, es idéntica al pronombre de primera persona del plural $g u$ 'nosotros'; sin embargo, la $z$, indicadora del paciente de tercera persona de plural y la $e$, indicadora del receptor de tercera persona del plural forman parte de la estructura morfológica del verbo de manera mucho más integrada que los correspondientes clíticos españoles. Se podría decir que esto aumenta la complejidad de la forma verbal euskérica; sin embargo, esa complejidad, en este caso concreto, se compensa con otra complejidad interpretativa del clítico español se, consistente en que no se marca el carácter plural del receptor. De esta manera, la distinción euskérica entre dakarzkiogu ' se los traemos (a él)' y dakarzkiegu 'se los traemos (a ellos)' en la que $o$ denota el receptor de tercera persona de singular y $e$ denota el receptor de tercera persona de plural, se pierde en español por causa del clítico se, que tiene las dos interpretaciones. Para expresar explícitamente cuál de ellas estamos utilizando se ha de utilizar un sintagma preposicional encabezado por la preposición $a$ seguida del pronombre correspondiente.

En resumidas cuentas, la comparación entre dakarzkiegu y 'se los traemos (a ellos)' no es describible adecuadamente diciendo que el verbo castellano es menos complicado que el verbo vasco, dado que estamos ante dos unidades indescomponibles (por más que en castellano se escriba como tres palabras y en euskera como solo una) que funcionan como tales en la sintaxis y en la prosodia y en distinta medida también en la morfología. Eso no quiere decir que morfológicamente hablando el verbo euskérico y el castellano sean idénticos. La integración morfológica de los indicadores personales es mayor en euskera que en castellano, pero esto no le da necesariamente una mayor complejidad al euskera frente al castellano. De hecho, hemos visto que el carácter clítico de los marcadores de persona del castellano no hace necesariamente más simples y transparentes las correspondientes formas del castellano en todos los casos, tal como hemos podido comprobar en la interpretación del clítico se.

\section{LOS PREJUICIOS ESCRITURISTAS Y LA SUPUESTA COMPLEJIDAD DEL EUSKERA}

En la sección anterior hemos visto cómo a veces la ortografía de las lenguas influye de forma notable en su comparación y en los juicios sobre su complejidad morfológica y estructural (Moreno Cabrera 2005). Buena parte de las clasificaciones tradicionales de las lenguas se suelen hacer sobre bases ortográficas y no tienen en cuenta las lenguas tal como se hablan efectivamente de forma natural. Un ejemplo de esto lo solemos tener en la clasificación que distingue las 
lenguas sintéticas de las analíticas. Los lingüistas que describen lenguas que nunca se han escrito, lo hacen sobre la base de la lengua oral espontánea, que tiene una tendencia importante hacia el sincretismo; por eso, muchas de estas lenguas se describen como polisintéticas. He aquí un ejemplo, de la lengua esquimal inuí tomado de Steinbergs (1996: 380)

\section{Qasu-iir-sar-vig-ssar-si-ngit-luinar-nar-puq \\ CANSADO-NO-CAUS-LUGAR-ADECUADO- ENCONTRAR-NO- COMPLETAMENTE -ALGUIEN -3SG \\ 'Alguien no encontró un lugar de descanso totalmente adecuado'}

Este tipo de expresión se debería comparar, para establecer una tipología lingüística, con expresiones análogas, es decir, extraídas de la lengua coloquial espontánea de las lenguas europeas. Sin embargo se suelen comparar con las formas escritas, regidas por unas convenciones ortográficas concretas, de esas lenguas. Por ejemplo, podríamos comparar la oración inuí precedente con la expresión castellana no han encontrado nada bueno en la que tenemos cinco elementos independientes separados por las reglas ortográficas de la lengua castellana. Sin embargo, si atendiéramos a la lengua hablada informal podemos encontrarnos muy fácilmente con una expresión equivalente, que podríamos transcribir sin forzarla injustificadamente, como noándàoconnábuèno (en ortografía normativa no han dado con nada bueno). Esto se debe a que la lengua hablada informal espontánea es mucho más sintética que lo que la ortografía nos da a entender. De hecho la expresión noándàoconnábuèno es mucho más frecuente y menos marcada que una proferencia cuidadosa de la oración ortográficamente regimentada no han encontrado nada bueno en la que se hacen pausas entre las palabras ortográficas. Por consiguiente, decir que el esquimal inuí es una lengua sintética y el español es una lengua analítica viene en gran medida ocasionado porque se está comparando el esquimal hablado informal (no hay lengua escrita formal) con el castellano estándar formal tal como se escribe. Es evidente, por tanto, que esta comparación está mal planteada y resuelta.

Como uno de los criterios para resaltar la supuesta complejidad del euskera frente al castellano, se aduce que el euskera es una lengua aglutinante en la que los morfemas se van poniendo en fila india, creando así palabras de gran complejidad.

He aquí una referencia en este sentido:«Las palabras que acompañan al sustantivo se unen a él, es decir, se aglutinan en una sola.» (Del Moral 2002: 192). Este autor da como ejemplo la palabra vasca gizonarekin 'con el hombre'. Lo curioso es que este criterio no se aplica al castellano y la razón fundamental es que la expresión con el hombre consta de tres palabras ortográficas. Ahora bien, no solo es verdad que esas tres palabras ortográficas se emiten como un solo elemento prosódico en el habla castellana oral espontánea, es que, como he observado antes, no se pueden separar en el discurso esos dos elementos que acompañan al sustantivo (es decir, la preposición con y el artículo él), tal como podemos apreciar en los ejemplos que siguen: 
- El niño vino con el hombre

- *El niño con vino el hombre

- *El niño el vino con hombre

- *Con el el niño vino hombre

Todo esto basta para mostrar dos cosas: que el artículo el y la preposición con se aglutinan con el sustantivo al que afectan y que el resultado obtenido constituye una unidad sintáctica. Dicho de otro modo, el castellano oral espontáneo es también una lengua aglutinante desde este punto de vista.

Se aduce que el euskera lleva más allá que otras lenguas estos procesos aglutinantes, de modo que una palabra puede presentar más afijos que una lengua no aglutinante. Consideremos, por ejemplo, la siguiente derivación típica del euskera:

Etor- $\Rightarrow d$-ator $\Rightarrow d$-atorr-en $\Rightarrow d$-atorr-en- $a \Rightarrow d$-atorr-en-a-ren $\Rightarrow$ $d$-atorr-en-a-ren-a

Se han añadido a la raíz inicial nada menos que cinco sufijos y uno de ellos (el afijo de definitud $-a$ ) dos veces.

Podríamos pensar que todo esto es por completo ajeno a una lengua como el castellano, pero si abandonamos la imagen de esta lengua que nos da la escritura y nos fijamos en el habla espontánea, podemos visualizar perfectamente la siguiente derivación, que traduce y es completamente paralela a la euskérica anterior:

Ven- $\Rightarrow$ vien-e $\Rightarrow$ que-vien-e $\Rightarrow$ el-que-vien-e $\Rightarrow d$-el-que-vien-e $\Rightarrow$ el-d-el-que-vien-e

Es decir, si consideramos la expresión el del que viene, no como una secuencia de cuatro palabras, sino como una palabra prosódica, entonces obtenemos una situación casi totalmente paralela a la euskérica. Al tema verbal ven- se le aglutinan cuatro prefijos y un sufijo; uno de ellos, el artículo el dos veces, como el sufijo $a$ del euskera. Aparte de las diferencias morfológicas entre datorrenarena y eldelqueviene, desde el punto de vista de la aglutinación, la única diferencia entre el euskera y el castellano es que el euskera es predominantemente sufijal y el castellano prefijal, en este ámbito concreto. Pero no cabe de duda de que las dos lenguas tienen un grado de aglutinación semejante.

Podemos comparar, en la misma línea el sistema de casos nominales, las formas casuales del pronombre zer 'qué', con las correspondientes formas del castellano oral espontáneo: 


\begin{tabular}{|c|c|c|}
\hline Euskera & Castellano oral & Castellano estándar \\
\hline ZER & KÉ & QUÉ \\
\hline ZERI & AKÉ & A QUÉ \\
\hline ZERTAN & ENKÉ & EN QUÉ \\
\hline ZEREN & DEKÉ & DE QUÉ \\
\hline ZERTAZ & CONKÉ & CON QUÉ \\
\hline ZERENTZAT & PA (RA)KÉ & PARA QUÉ \\
\hline
\end{tabular}

Queda claro lo que ya hemos visto antes: que el castellano es una lengua aglutinante prefijal y el euskera lo es sufijal.

Estas variaciones sufijales nominales del euskera se suelen denominar casos por analogía con lo que ocurre en latín y griego clásicos. En su aguda y clarificadora gramática de euskera, de Rijk afirma sobre esta cuestión:

Más que igualar las terminaciones vascas con los marcadores de caso del latín y lenguas similares, ¿no sería preferible igualarlas con preposiciones, familiares para nosotros por el inglés y muchas otras lenguas? Después de todo, desde un punto de vista estructural, los sintagmas nominales vascos pueden verse como imágenes especulares perfectas de sus contrapartidas inglesas. [...] Parece que todo lo que tenemos que hacer es reemplazar el término 'preposición' por ‘posposición' con el fin de que la situación en vasco encaje a la perfección.

(De Rijk 2008: 34)

Esta observación de de Rijk se ajusta en buena medida a lo que estoy proponiendo aquí, con una diferencia de enfoque importante. Lo que estoy sugiriendo es que las preposiciones del castellano son en realidad prefijos de caso y que lo que tiene el euskera son sufijos de caso. La integración morfológica de los prefijos suele ser, en general, menor que la de los prefijos. Comparemos, por ejemplo, los prefijos castellanos pre- y pos- con los sufijos -ismo e -ista. No hay duda de que no son palabras autónomas sino afijos. Ahora bien, la integración morfológica del sufijo es mayor que la del afijo. Esto se puede demostrar fácilmente mediante la prueba de la conjunción de afijos. Se admite en los prefijos, pero no se admite en los sufijos, tal como podemos ver en los siguientes ejemplos:

- La preparación al pre- o posparto

- *Los conceptos de consumismo o -ista

- Los conceptos de consumismo o consumista

Esta mayor integración morfológica del sufijo es notada por de Rijk precisamente utilizando este criterio: 
En vasco está excluida la conjunción de terminaciones casuales. El sustantivo implicado ha de repetirse, o como mínimo debe ser retomado por un pronombre. De esta manera: apaizekin ala apaizez? sorginarentzat eta sorginarengatik. O : sorginarentzat eta harengatik 'para la bruja y a causa de ella'

(De Rijk 2008: 34)

Es muy posible que esta restricción no sea exclusiva del euskera, dado que, como acabamos de ver, es también aplicable a los sufijos castellanos.

Volvamos al problema que supone la comparación de versiones escritas de las lenguas y a la imagen falseada que nos puede dar esta comparación acerca de la supuesta complejidad o simplicidad de una lengua determinada respecto de otra.

Si comparamos una oración del euskera escrito con su correspondiente traducción al castellano escrito, obtenemos una visión del castellano más analítica, tal como muestra el índice de síntesis de Greenberg (1954: 12), que se obtiene dividiendo el número de unidades significativas mínimas o monemas por el número de palabras $(\mathrm{M} / \mathrm{P})$ :

\section{Oración del euskera escrito estándar}

EZ DAKIT ZERTARAKO ETORRARAZI NAUTEN

EZ DAKI-T ZER-TARAKO ETOR-ARAZI NA-U-TE-N

NEG SABER-1. ${ }^{a}$ SG QUÉ-PARA VENIR-HECHO 1. ${ }^{a}$ SG-HAB-3. ${ }^{a} \mathrm{Pl}$ COMP

Índice de síntesis: 11 monemas y 5 palabras; $11 / 5=2$ '2

\section{Oración del castellano escrito estándar}

\section{NO SÉ PARA QUÉ ME HAN HECHO VENIR}

NEG Saber-1. aSG PREP- QUÉ 1. aSG HABER-3. aSG HECHO VEN-INF

Índice de síntesis: 11 monemas y 8 palabras; 11/8 = 1’37

Cuanto más se acerque una lengua al valor 1 respecto del índice de síntesis, más analítica será, ya que si a cada palabra le corresponde una unidad significativa el numerador y el denominador serán idénticos y, por tanto, la división será igual a uno. En el caso que nos ocupa, observamos que el índice de síntesis de la frase euskérica es 2'2 y el de la correspondiente oración castellana es de 1'3. Por tanto, se deduce, si estos datos fueran representativos de las lenguas, que el euskera es más sintético que el castellano.

Pero si a continuación comparamos la oración del euskera escrito con su correspondiente del castellano oral espontáneo, entonces los resultados son muy distintos: 


\section{Oración del castellano oral espontáneo}

[nosé paké mànécho benír] (No sé para qué me han hecho venir)

Índice de síntesis: $11 / 4=2 ’ 75$

Ahora el índice de síntesis es superior al de la oración euskérica porque hay cuatro palabras prosódicas y once elementos significativos mínimos.

Es decir, ahora podríamos deducir que el castellano hablado espontáneo sería más sintético que el euskera. Sin embargo aquí estamos haciendo algo que es ilegítimo, según lo dicho en la primera sección de este trabajo, ya que comparamos el euskera escrito con el castellano oral espontáneo, cuando lo que habría que hacer es comparar el euskera oral espontáneo con el castellano oral espontáneo.

Es aquí donde vemos también que la ortografía no siempre hace justicia al carácter sintético del euskera. En efecto, si en vez de considerar el euskera escrito nos fijamos en el hablado, veremos que elementos que se expresan de forma analítica en la escritura aparecen de forma sintética y aglutinante en el habla.

En primer lugar, lo que en la escritura se concibe como conjugación verbal perifrástica, en el habla oral espontánea puede verse en muchos casos como unidades aglutinadas. He aquí algunos ejemplos de esta conjugación analítica aglutinada:

- [esandut] (Txillardegi 1982:105)

- amaitzot (= amaitzen dot 'termino') (Txillardegi 1982:116)

- eukitzeitu (= eukitzen ditu 'los tengo’) (Txillardegi 1982:116)

- sártukot (=sartuko dot, 'lo meteré’) (Hualde y Bilbao 1992: 51)

- ésangostesu (=esango dostesu 'me lo dirás') (Hualde y Bilbao 1992: 51)

- ikúsikosue (=ikusiko dosue 'veréis') (Hualde y Bilbao 1992: 51)

- sinistasendut 'creo', padecituçuen 'padeció', etorricoda 'vendrá', resuscitatusen 'resucitó' (Mitxelena 1990: 163)

La negación es un elemento que se aglutina a la palabra que afecta en forma de un prefijo negativo:

- [enekien] 'ez nekien' ('no sabía)/ [enuen] 'ez nuen' ('no tenía')/ [enais] 'ez naiz'('no soy') (Txillardegi 1982: 245)

- elauke 'es lauke'('no tendría'), enabil 'es nabil' ('no voy'), estot 'es dot'('no lo tiene', estait 'es dakit' ('no sabe') (Hualde y Bilbao 1992: $50)$

Por otra parte, la partícula bait funciona también como un prefijo aglutinado, cosa que incluso se suele reflejar también en la ortografía: 
- [bainuke] 'bait nuke' ('porque yo tendría') / [bailuke] 'bait luke' ('porque él tendría') (Txillardegi 1982: 283)

La partícula $b a$ funciona como un sufijo consecuencial (ondoriozko lokailua):

- es da(k)it ba [estai'pa] (' pues no sé’)(Hualde y Bilbao 1992: 20)

- joan zaitez ba 'pues ven' (Euskaltzaindia 1990: 152)

Muy frecuente en euskera es el -(e)ta enclítico con un sentido causal

- Jon berehala etorriko da, azkarra daTA 'Juan vendrá en seguida porque es rápido' (Rotaetxe 2004: 125).

- Buruko mina duTA, Manu etxean geratu da 'Manu se ha quedado en casa porque tiene dolor de cabeza'(Rotaetxe 2004: 125).

- Eguraldi euritsua duguTA, museora joango gara 'Como el tiempo está lluvioso, iremos al museo'(Rotaetxe 2004: 126).

- Gaur, jaia dela dirudi hiriko kaleak hutsik daudeTA 'Hoy parece fiesta, porque las calles están vacías' (Rotaetxe 2004: 129).

En todos estos casos podemos comprobar que el euskera es algo más sintético de lo que se induce a través de la escritura. En la oración euskérica analizada antes, podríamos perfectamente considerar que $e z$ dakit forman una unidad en la lengua hablada espontánea; por ello, el índice de síntesis habría de ser 11/4 = 2'75. Este índice es idéntico al obtenido cuando analizamos la traducción correspondiente al castellano oral espontáneo. De esta manera, podemos comprobar cómo la comparación entre las lenguas da unos resultados claramente sesgados y deformados cuando mezclamos las convenciones de la escritura con las características del discurso hablado espontáneo, que, en general, es mucho más trabado y aglutinante que el discurso escrito.

Podría pensarse que el discurso oral espontáneo no es más que una versión rápida y deformada por los condicionantes de la actuación lingüística de la versión escrita. Sin embargo esto va contra uno de los principios básicos de la lingüística contemporánea: el de la primacía absoluta de la lengua hablada sobre la escrita. En una sección titulada «el habla, fundamento del lenguaje» de su introducción a la lingüística general, R. H. Robins nota dos hechos fundamentales: primero que la lengua hablada precede a la escrita por, como mínimo decenas de miles de años:

Debemos suponer o imaginar que durante muchos milenios ésta [el habla] era la única manifestación del lenguaje, antes de que se originaran los sistemas de escritura, hará unos 5.000 años. Hay hoy día muchas comunidades en las que se hablan lenguas para las que no se ha imaginado ningún lenguaje escrito. 
Un segundo hecho notado por Robins es aún más decisivo:

Podemos observar que, contrariamente a una muy extendida opinión, las lenguas de las comunidades totalmente analfabetas no difieren en ningún aspecto importante, en cuanto a los sonidos se refiere, de las lenguas de los pueblos que por mucho tiempo han poseído una lengua escrita y son conocidos como focos importantes de la civilización mundial.

(Robins 1995: 129-130)

Aquí conviene ampliar el alcance de la afirmación de Robins, las lenguas de las comunidades que no tiene escritura no difieren en ningún aspecto lingüístico esencial (fónico, morfológico, sintáctico, semántico y pragmático) de las lenguas que tienen una escritura. Eso no quiere decir que las lenguas escritas no tengan sus propias peculiaridades, pero las tienen en tanto que lenguas artificiales, no como lenguas naturales.

En tercer lugar, la precedencia del habla sobre la escritura no sólo es diacrónica o histórica, sino que también es sincrónica:

Por otra parte, una breve reflexión nos muestra que en las comunidades alfabetizadas el habla precede a la escritura en la adquisición del lenguaje por los niños normales y que la capacidad del lenguaje hablado, del habla, excede con mucho a la del lenguaje escrito (...) de cada uno de los miembros de la comunidad.

(Robins 1995: 129-130)

Sobre este postulado esencial de la lingüística contemporánea, la idea de que la lengua hablada espontánea o informal es una realización incompleta e imperfecta de la lengua escrita es absolutamente insostenible. Por ello, no tiene sentido decir, como se hace a menudo, que, en el habla, la secuencia de los palabras separadas el hombre o ez dakit se funde en una secuencia única elhombre o ezdakit. Esto es así porque estamos partiendo de la lengua escrita para analizar la hablada, lo cual no concuerda con el principio básico de la lingüística contemporánea de la primacía del habla sobre la escritura. La única forma de razonar de acuerdo con este principio es enfocar la cuestión desde el punto de vista de la lengua hablada espontánea para decir que en la escritura las secuencias elhombre y ezdakit se separan en dos elementos ortográficamente distintos. Esto es precisamente lo que casi nunca hacen los lingüistas, a pesar de que reconocen en teoría esa primacía analítica del habla. La razón de ello radica en el poder de la ideología de la lengua escrita.

\section{CONCLUSIONES}

En este trabajo he revisado dos conceptos que suelen ir asociados en los juicios que hacemos sobre de las lenguas. Se trata del concepto de complejidad y del concepto de dificultad de aprendizaje de las lenguas. Se suele suponer que las 
lenguas más complejas son más difíciles de aprender que las menos complejas. La complejidad se suele medir por el índice de síntesis en las lenguas: las lenguas supuestamente más sintéticas serán más complejas que las supuestamente más analíticas, que serán más claras y fáciles de aprender, porque se supone que tienen menos reglas.

Hemos visto que los juicios de dificultad y facilidad se basan o bien en las percepciones engañosas de la lengua escrita o bien en impresiones superficiales igualmente engañosas. También he insistido en que la lengua oral espontánea no es una realización defectuosa o incompleta de la lengua escrita.

He aducido además que la escritura nos da una visión distorsionada de la lengua oral espontánea. A pesar de ello, una gran mayoría de las descripciones gramaticales de las lenguas europeas o de origen europeo, se basan en la lengua escrita, no en la lengua oral espontáneas.

La idea que defiendo es que todas las lenguas tienen un grado de complejidad similar por dos factores fundamentales: se adecuan a las condiciones psicofisiológicas que caracterizan a todos los seres humanos, y son transmisibles de generación en generación de forma espontánea, sin la intervención de la escuela. De todo ello cabe deducir que el punto de vista de que hay lenguas más complejas que otras no tiene sustento lingüístico alguno y que, por consiguiente, ni el euskera, ni el húngaro, ni el finés son idiomas intrínsecamente complejos (frente a las demás lenguas europeas) por más que quienes las aprenden como lenguas segundas digan lo contrario y por más que quienes las usan como lenguas primeras intenten a veces valorarlas y ensalzarlas afirmando que son lenguas muy difíciles o imposibles de aprender por parte de los extranjeros.

\section{REFERENCIAS BIBLIOGRÁFICAS}

Coulson, M. (1976): Sanskrit. An introduction to this classical language, Oxford: Hodder and Stoughton.

DAHL, Ö. (2004): The Growth and Maintenance of Linguistic Complexity, Amsterdam, John Benjamins 256-259.

De RiJK, R. P. G. (2008): Standard Basque. A Progressive grammar, Cambridge: The MIT Press.

Del Moral, R. (2002): Diccionario Espasa de las Lenguas del Mundo, Madrid. Espasa Calpe.

EusKalTZAINDIA (1987): Euskal Gramatika. Lehen Urratsak-II. Bilbo.

EuSKALTZAINDIA (1990): Euskal Gramatika. Lehen Urratsak-III. Bilbo.

GreENBERG, J. (1954): «A Quantitative Approach to the Morphological Typology of Language» en K. Denning y S. Kemmer (eds.) On Language. Selected Writings of Joseph H. Greenberg, Stanford: Stanford University Press, 1990: 3-25.

Hualde, J. I. \& X. Bilbao (1992): A phonological study of the Basque dialect of Getxo, Donostia, Gipuzkoako Foru Aldundia. 
Kusters, W. (2003): Linguistic Complexity.The Influence of Social Change on Verbal Inflection, Utrecht: LOT.

LARRAMENDI, M. (1728): De la antigüedad y universalidad del vascuence en España, Donostia, Roger Editor, 2000.

Michelena, L. (1990): Textos Arcaicos Vascos, Diputación Foral de Navarra, San Sebastián.

Moreno CABrera, J. C. (2005): «Tipología Lingüística y escritura» en La Lengua y Su Naturaleza Dinámica. Homenaje a Ivan Kanchev en su 70 aniversario, Sofía, 2005, páginas 57-67.

Moreno Cabrera, J. C. (2006): De Babel a Pentecostés. Manifiesto plurilingüista, Barcelona, Horsori.

Moreno Cabrera, J. C. (2008): El Nacionalismo Lingüístico. Una ideología destructiva, Barcelona: Península.

NogueIRA, J. y G. Turover (1992): Diccionario ruso-español, Madrid: Rubiños 1860.

RAE (1973): Esbozo de una Nueva Gramática de la Lengua Española, Madrid: Espasa Calpe.

Robins, R. H. (1995): Lingüística General. Estudio introductorio, Madrid: Gredos.

RotAeTXE, K. (2004): «-( e ) ta enklitikoa sailkapen eskalarrean» Fontes Linguae Vasconum, XXXVI, 95: 115-139.

Steinbergs, A. (1996): «The classification of languages», en W. O'Grady, M. DobroVOLSKY y F. KATAMBA (eds.) Contemporary Linguistics. An Introduction, Londres, Longman, 1996: 372-415.

TXILlardegi (1982): Euskal Fonologia, EV.

ZubIRI, I. y E. (2000): Euskal Gramatika Osoa, Bilbo: Didaktiker. 